\title{
Sex-specific Action of Insulin to Acutely Increase the Metabolic Clearance Rate of Dehydroepiandrosterone in Humans
}

John E. Nestler*‡ and Ziad Kahwash*

$*$ Department of Internal Medicine and ${ }^{\ddagger}$ Department of Obstetrics and Gynecology, Medical College of Virginia/Virginia Commonwealth University, Richmond, Virginia 23298

\begin{abstract}
To test the hypothesis that insulin acutely enhances the metabolic clearance rate (MCR) of dehydroepiandrosterone in humans, the effect of a short-term insulin infusion on the MCR of dehydroepiandrosterone was assessed in 10 men and 7 women. After an overnight fast, dehydroepiandrosterone was infused at $3.47 \mu \mathrm{mol} / \mathrm{h}$ for $6.5 \mathrm{~h}$. At $240 \mathrm{~min}$, a hyperinsulinemic-euglycemic clamp was begun by infusing insulin at $21.5 \mathrm{pmol} / \mathrm{kg}$ per min for $2.5 \mathrm{~h}$. MCR of dehydroepiandrosterone was calculated at baseline (210-240 $\mathrm{min}$ ) and during the insulin infusion (360-390 min). A control study was conducted at least 1 wk later, in which $0.45 \%$ saline was substituted for the hyperinsulinemic-euglycemic clamp. During the insulin clamp study, serum insulin rose from $34 \pm 2$ to $1084 \pm 136 \mathrm{pmol} /$ liter $(P=0.0001)$ in men and from $40 \pm 5$ to $1357 \pm 175 \mathrm{pmol} / \mathrm{liter}(P=0.0003)$ in women, while serum glucose remained constant in both groups. MCR of dehydroepiandrosterone rose in men during the insulin infusion from $2443 \pm 409$ to $3599 \pm 500$ liters/ $24 \mathrm{~h}(P=0.003)$, but did not change during the control saline infusion. In contrast, MCR of dehydroepiandrosterone in women did not change in the insulin clamp study during insulin infusion ( $2526 \pm 495$ liters $/ 24 \mathrm{~h}$ at baseline vs. $2442 \pm 491$ liters $/ 24 \mathrm{~h}$ during insulin infusion; $P=\mathbf{0 . 7 8}$ ). These findings suggest that insulin acutely increases the MCR of dehydroepiandrosterone in men but not in women. (J. Clin. Invest. 1994. 94:1484-1489.) Key words: dehydroepiandrosterone • insulin • metabolism • steroid • metabolic clearance rate
\end{abstract}

\section{Introduction}

The steroid dehydroepiandrosterone (DHEA) ${ }^{1}$ is derived primarily from the adrenal glands in both men and women (1) DHEA exhibits a very high turnover, which is characteristic

Presented in abstract form at the 1994 Annual Scientific Meeting of The Endocrine Society, Anaheim, CA, 15-18 June 1994.

Address correspondence to John E. Nestler, M.D., Medical College of Virginia, P.O. Box 980111, Richmond, VA 23298-0111.

Received for publication 8 April 1994 and in revised form 2 June 1994

1. Abbreviations used in this paper: DHEA, dehydroepiandrosterone; MCR, metabolic clearance rate; MCR $_{\mathrm{DHEA}}$, metabolic clearance rate of dehydroepiandrosterone.

J. Clin. Invest.

(c) The American Society for Clinical Investigation, Inc.

0021-9738/94/10/1484/06 \$2.00

Volume 94, October 1994, 1484-1489 of a biologically active hormone (2), and mounting evidence suggests that DHEA may play an important biological role in preventing heart disease in men (3-10). In animal studies, administration of DHEA protects against the development of experimentally induced aortic $(11,12)$ and coronary (13) atherosclerosis. DHEA may exert these cardioprotective actions by inhibiting cellular proliferation (14), lowering serum lipids $(15,16)$, and suppressing platelet reactivity (17). Moreover, some studies in humans (18-20) and animals (21-23), although not all $(15,24,25)$, suggest that DHEA may improve insulin sensitivity.

Circulating DHEA demonstrates a striking and unexplained age-related decline. Peak serum DHEA levels occur around age 20-30 yr, decline progressively thereafter, and are reduced by $>90 \%$ by age $80 \mathrm{yr}(26,27)$. This pattern contrasts markedly with adrenal glucocorticoids, whose serum levels and responsiveness to adrenocorticotropin remain relatively stable with aging (1). While it has been known for some time that adrenal androgen metabolism is regulated differently from adrenal glucocorticoids or mineralocorticoids, little is known about the mechanism(s) subserving the distinct metabolism of DHEA.

Insulin may regulate DHEA metabolism in men. Serum DHEA levels decline progressively in men during an acute elevation of circulating insulin (24). Conversely, chronic reduction of circulating insulin in men is associated with a rise in serum DHEA levels in some (27a), although not all (28), studies.

Evidence suggests that a mechanism for insulin's reduction of circulating DHEA in men (24) might be enhanced DHEA clearance. For example, the metabolic clearance rate (MCR) of adrenal androgens is increased two- to fivefold in obesity (2932 ), which is an insulin-resistant and hyperinsulinemic state. The MCR of adrenal androgens declines with fasting $(31,33)$, even when weight loss is minimal but circulating insulin presumably falls. Although investigators have attributed the elevated MCR of adrenal androgens in obesity to increased deposition of androgens into fat tissue, studies have failed to show a clear relationship between indices of overall adiposity (body mass index or percent ideal body wt) and serum adrenal androgen levels $(34,35)$. In contrast, it has been reported that a significant positive correlation exists between fasting serum insulin and the MCR of adrenal androgens in women $(29,32)$. On the basis of the above observations, it seems likely that the hyperinsulinemia of obesity is directly responsible for the increased MCR of adrenal androgens, although fat tissue may act as a storage site.

To test the hypothesis that insulin acutely enhances the MCR of DHEA ( MCR $_{\text {DHEA }}$ ) in humans, the effect of a shortterm insulin infusion on the $\mathrm{MCR}_{\mathrm{DHEA}}$ was assessed in both men and women. We observed a sex-based disparity in insulin action, in that insulin increased the $\mathrm{MCR}_{\text {DHEA }}$ in men but not in women. 
Table I. Serum DHEA Concentrations and the $M_{C} R_{D H E A}$ in Men and Women during the Hyperinsulinemic-Euglycemic Clamp Study

\begin{tabular}{|c|c|c|c|c|c|}
\hline Subject & $\begin{array}{c}\text { Mean [DHEA] from } \\
-20-0 \mathrm{~min}\end{array}$ & $\begin{array}{l}\text { Mean [DHEA] from } \\
210-240 \mathrm{~min}\end{array}$ & $\begin{array}{l}\text { Mean [DHEA] from } \\
360-390 \mathrm{~min}\end{array}$ & Baseline $\mathbf{M C R}_{\text {DHEA }}$ & $\begin{array}{c}\text { MCR }_{\mathrm{DHEA}} \text { during } \\
\text { insulin-glucose clamp }\end{array}$ \\
\hline & nmolliter & nmolniter & nmolliter & liters $/ 24 h$ & liters $/ 24 h$ \\
\hline \multicolumn{6}{|l|}{$\operatorname{Men}(n=10)$} \\
\hline 1 & 14.7 & 56.6 & 37.2 & 1984 & 3688 \\
\hline 2 & 27.8 & 82.9 & 72.8 & 1472 & 3607 \\
\hline 3 & 15.5 & 72.0 & 38.6 & 1472 & 3607 \\
\hline 4 & 40.0 & 73.1 & 54.7 & 2515 & 5666 \\
\hline 5 & 33.5 & 49.0 & 46.7 & 5347 & 6304 \\
\hline 6 & 21.0 & 76.5 & 70.0 & 1498 & 1695 \\
\hline 7 & 20.5 & 41.3 & 38.0 & 3996 & 4744 \\
\hline 8 & 14.7 & 66.8 & 51.2 & 1599 & 2281 \\
\hline 9 & 35.3 & 82.6 & 68.4 & 1759 & 2514 \\
\hline 10 & 34.2 & 64.5 & 57.0 & 2745 & 3648 \\
\hline Mean \pm SEM & $25.7 \pm 3.0$ & $66.5 \pm 4.4$ & $53.5 \pm 4.3$ & $2443 \pm 409$ & $3599 \pm 500 *$ \\
\hline \multicolumn{6}{|l|}{ Women $(n=7)$} \\
\hline 1 & 16.4 & 93.5 & 103.3 & 1078 & 957 \\
\hline 2 & 32.3 & 73.9 & 81.2 & 1997 & 1701 \\
\hline 3 & 22.3 & 87.7 & 76.5 & 1273 & 1535 \\
\hline 4 & 17.7 & 56.0 & 48.1 & 2175 & 2740 \\
\hline 5 & 16.9 & 47.5 & 59.1 & 2719 & 1971 \\
\hline 6 & 17.6 & 35.3 & 41.6 & 4690 & 3466 \\
\hline 7 & 16.1 & 38.3 & 33.7 & 3749 & 4721 \\
\hline Mean \pm SEM & $19.9 \pm 2.2$ & $61.7 \pm 8.9$ & $63.4 \pm 9.4$ & $2526 \pm 495$ & $2442 \pm 491$ \\
\hline
\end{tabular}

*P $=0.003$ when compared to baseline value in same group.

\section{Methods}

Study design. A total of 10 men and 7 premenopausal women were enrolled into the study, and all subjects completed the study. Subjects were healthy, nonobese, and 20-30 yr old. The study was approved by the Committee on the Conduct of Human Research at the Medical College of Virginia, and informed written consent was obtained from each subject.

Subjects were studied on two occasions. For men the two study sessions were separated from one another by 1 wk. For normally cycling women $(n=4$; subjects $1,2,3$, and 6 in Table I), the two study sessions were separated by $28 \mathrm{~d}$ and each was performed during the early follicular phase of the menstrual cycle (days 3-5). Women taking oral constant-dose estrogen contraceptives $(n=2$; subjects 4 and 5 in Table I) were asked to take the medication daily for $6 \mathrm{wk}$, and were studied during weeks 5 and 6 . The two study sessions were separated by 1 wk in the single woman (subject 7 in Table I) using a transdermal delivery system contraceptive (Norplant ${ }^{\oplus}$; Wyeth-Ayerst Laboratories, Philadelphia, PA).

Exogenously infused DHEA is taken up by the ovary in vivo (36) Therefore, MCR $_{\text {DHEA }}$ was determined by the nonisotopic method described by Bélisle et al. (37) to optimize safety for and recruitment of premenopausal women. This methodology yields results similar to those obtained by isotopic methods (37), and has been utilized by other investigators for this purpose $(29,32)$.

For the first (experimental) study session, subjects were admitted to the General Clinical Research Center after an overnight fast at 0800 hours and two intravenous catheters were placed in contralateral antecubital veins of each subject: one for blood withdrawal and the other for DHEA, insulin, and glucose infusions. After baseline blood samples were obtained at 0830 hours ( time 0 ), crystallized and sterilized DHEA (dissolved in $33 \%$ ethanol and $0.9 \%$ saline) was administered intravenously at a rate of $3.47 \mu \mathrm{mol} / \mathrm{h}(1.0 \mathrm{mg} / \mathrm{h})$ for $6.5 \mathrm{~h}$. Blood samples were drawn for determination of DHEA, insulin, and glucose concentra- tions at $(-20,-10,0,30,60,90,120,150,180,210,220,230$, and $240 \mathrm{~min}$. Serum DHEA levels attain steady state after $\sim 3 \mathrm{~h}$ of a constant DHEA infusion $(29,32)$, and steady state of serum DHEA in this study at $210,220,230$, and 240 min of DHEA infusion was documented using a mixed-model ANOVA. The mean baseline (preinfusion) DHEA concentration was considered the average of the $-20,-10$, and $0 \mathrm{~min}$ values. The four serum DHEA values from 210-240 min were used to calculate the baseline $\mathrm{MCR}_{\mathrm{DHEA}}$ as previously described $(29,32,37)$, using the formula: $\mathrm{MCR}_{\mathrm{DHEA}}=$ DHEA infused $(\mu \mathrm{mol} / 24 \mathrm{~h}) \div \Delta$ DHEA concentration at plateau ( $\mathrm{nmol} /$ liter), where $\triangle$ DHEA concentration at plateau represents the mean serum concentration of DHEA at equilibrium minus the mean baseline (preinfusion) DHEA level.

A hyperinsulinemic-euglycemic clamp was initiated immediately after the 240-min blood sample was drawn and while the DHEA infusion continued. This was done in a manner similar to studies we published previously $(24,38,39)$. The insulin infusion was designed to attain a high physiologic serum insulin concentration of $\sim 1200 \mathrm{pmol} /$ liter. At this concentration, the metabolic effects of insulin should attain steady state after $2 \mathrm{~h}$. Each subject received an intravenous bolus dose of $21.5 \mathrm{nmol}(3 \mathrm{U}$ ) human regular insulin (Humulin ; Eli Lilly and Co., Indianapolis, $\mathrm{IN}$ ), followed immediately by an insulin infusion at a rate of $21.5 \mathrm{pmol} / \mathrm{kg}$ per min $(3.0 \mathrm{mU} / \mathrm{kg}$ per min $)$ for $2.5 \mathrm{~h}$ infused via a Harvard pump. Euglycemia was maintained as previously described (15) by checking the blood glucose level every 5 min and adjusting the rate of a $25 \%$ dextrose infusion as needed. Blood samples for determination of DHEA, insulin, and glucose concentrations were obtained at $270,300,330,360,370,380$, and $390 \mathrm{~min}$. The four DHEA values from 360-390 min were used to calculate $\mathbf{M C R}_{\mathrm{DHEA}}$ under hyperinsulinemic conditions.

The second (saline control) study session was performed identically to the hyperinsulinemic-euglycemic clamp session, except that a saline infusion was substituted for the insulin and dextrose infusions. DHEA alone was infused from 0-240 min, and the baseline $M^{M C R_{D H E A}}$ was determined during $210-240 \mathrm{~min}$. Starting at $240 \mathrm{~min}$, while the DHEA 
infusion continued, a 2.5 -h $0.45 \%$ saline infusion was initiated at a rate equal to the combined insulin and dextrose infusion rates during the first study session. The saline infusion rate was adjusted every $15 \mathrm{~min}$, and the $\mathrm{MCR}_{\mathrm{DHEA}}$ determined again during 360-390 min. The study sessions were not randomized, because the individual hourly saline infusion rates required for each subject during control sessions could not be anticipated a priori.

Assays. Blood samples were centrifuged immediately, and sera separated and stored at $-20^{\circ} \mathrm{C}$ in glass tubes until assayed. Serum insulin levels were determined by a double antibody radioimmunoassay (Diagnostic Products Corp., Los Angeles, CA). Serum glucose levels were determined by the glucose oxidase method (Glucose Analyzer; Beckman Instruments, Inc., Fullerton, CA). Serum DHEA concentrations were determined after organic extraction from serum by solid phase radioimmunoassay (Diagnostic Products Corp.). ${ }^{3} \mathrm{H}$-labeled steroid was added to serum before extraction to correct for procedural losses. To avoid interassay variation (which is $7 \%$ for the insulin assay and $10 \%$ for the DHEA assay), all hormone measurements were determined in a single assay. The intraassay coefficients of variation for the insulin and DHEA assays were $<5 \%$ and $<7 \%$, respectively.

Statistical analysis. Results are reported as mean \pm SEM. Within a group, results before treatment (baseline MCR) were compared to those during treatment (MCR during insulin or saline infusion) by Student's two-tailed paired $t$ test. Comparisons between groups were made by Student's two-tailed unpaired $t$ test. $P<0.05$ was considered significant.

\section{Results}

Results in men. Mean age of the men was $24.2 \pm 0.5 \mathrm{yr}$, and mean body mass index was $24.1 \pm 0.6 \mathrm{~kg} / \mathrm{m}^{2}$.

In the hyperinsulinemic-euglycemic clamp study, serum insulin rose from a basal concentration (mean of -20-240 min values) of $34 \pm 2$ to $1084 \pm 136 \mathrm{pmol} / \mathrm{liter}$ (mean of $270-390$ min values) during the insulin infusion $(P=0.0001$; Fig. 1$)$. In contrast, serum insulin fell slightly but significantly during the saline control study $(50 \pm 4 \mathrm{pmol} /$ liter at baseline vs. $34 \pm 2$ $\mathrm{pmol} /$ liter during saline infusion; $P<0.03$; Fig. 1). Serum glucose remained constant at the fasting level during both the hyperinsulinemic-euglycemic clamp and saline control studies (Fig. 1).

In the hyperinsulinemic-euglycemic clamp study, MCR $_{\text {DHEA }}$ rose in each man during the insulin infusion (Table I). Mean $\mathrm{MCR}_{\mathrm{DHEA}}$ rose by $47 \%$ from a baseline value of $2443 \pm 409$ to $3599 \pm 500$ liters $/ 24 \mathrm{~h}$ during the insulin infusion $(P=0.003$; Table I and Fig. 2).

Baseline MCR $_{\text {DHEA }}$ during the saline control study did not differ from baseline MCR $_{\text {DHEA }}$ during the insulin study $(2443 \pm 409$ vs. $2560 \pm 323$ liters $/ 24$ h, respectively; $P=\mathrm{NS}$; Fig. 2). In the saline control study, $M_{C R_{\text {DHEA }}}$ did not change during the saline infusion $(2560 \pm 323$ liters $/ 24 \mathrm{~h}$ at baseline vs. $2313 \pm 356$ liters $/ 24 \mathrm{~h}$ during saline infusion; $P=\mathrm{NS}$; Fig. 2).

Results in women. Mean age of the women was $23.7 \pm 1.3$ $\mathrm{yr}$, and mean body mass index was $22.0 \pm 1.0 \mathrm{~kg} / \mathrm{m}^{2}$. The women did not differ from the men with respect to age $(P$ $=0.70)$. Although the women tended to have a lower body mass index than the men, this was not statistically significant $(P=0.07)$.

In women, serum insulin rose in the hyperinsulinemic-euglycemic clamp study from a mean of $40 \pm 5 \mathrm{pmol} / \mathrm{liter}$ to $1357 \pm 175 \mathrm{pmol} /$ liter during the insulin infusion $(P=0.0003$; Fig. 1). In contrast, serum insulin fell slightly but significantly during the saline control study $(47 \pm 8 \mathrm{pmol} /$ liter at baseline vs. $37 \pm 5$ pmol/liter during saline infusion; $P<0.05$; Fig. 1$)$.
During both the hyperinsulinemic-euglycemic clamp and saline control studies serum glucose remained constant at the fasting level (Fig. 1).

In contrast to the men, insulin did not affect the $\mathbf{M C R}_{\mathrm{DHEA}}$ in women (Table I and Fig. 2). In the hyperinsulinemic-euglycemic clamp study, the $\mathrm{MCR}_{\mathrm{DHEA}}$ during the insulin infusion did not differ from that at baseline $(2442 \pm 491$ liters $/ 24 \mathrm{~h}$ versus $2526 \pm 495$ liters $/ 24 \mathrm{~h}$, respectively; $P=0.78$ ) (Fig. 2 ).

Of note, in the hyperinsulinemic-euglycemic clamp study, the basal $\mathrm{MCR}_{\text {DHEA }}$ did not differ between the normally cycling women $(n=4)$ or the women on contraceptive therapy $(n=3)$ $(2259 \pm 834$ liters $/ 24$ h vs. $2881 \pm 462$ liters $/ 24$ h, respectively; $P=0.58)$. Furthermore, insulin did not alter the $\mathrm{MCR}_{\mathrm{DHEA}}$ in either group (normally cycling women: $2259 \pm 834$ liters $/ 24 \mathrm{~h}$ vs. $1915 \pm 541$ liters $/ 24 \mathrm{~h}$ during insulin infusion; $P=0.35$; women on contraceptive therapy: $2881 \pm 462$ liters $/ 24 \mathrm{~h}$ vs. $3144 \pm 818$ liters $/ 24 \mathrm{~h}$ during insulin infusion; $P=0.66$ ).

Baseline $\mathrm{MCR}_{\text {DHEA }}$ during the saline control study did not differ from baseline $\mathrm{MCR}_{\mathrm{DHEA}}$ during the insulin study ( $2524 \pm 209$ liters $/ 24$ h vs. $2526 \pm 495$ liters $/ 24$ h, respectively; $P=$ NS; Fig. 2). Moreover, the $\mathrm{MCR}_{\mathrm{DHEA}}$ did not change during the saline control study $(2524 \pm 209$ liters $/ 24 \mathrm{~h}$ at baseline vs. $2380 \pm 203$ liters $/ 24$ h during saline infusion; $P=$ NS; Fig. 2 ).

\section{Discussion}

The findings of the present study indicate that insulin acutely increases the $\mathrm{MCR}_{\mathrm{DHEA}}$ in men. The $\mathrm{MCR}_{\mathrm{DHEA}}$ rose in each of the 10 men during acute hyperinsulinemia, but did not change during control saline infusions. The serum insulin concentrations attained during the insulin infusions were within the physiologic range, in that they were similar to those that might be observed after a meal. Hence, the study's findings support the idea that insulin acts as a physiologic regulator of DHEA metabolism in men (7). A theoretical mechanism by which insulin could increase the $\mathrm{MCR}_{\text {DHEA }}$ in men might involve insulin's well-described vasodilatory action (40-43). By acting as a vasodilator, insulin would acutely enhance delivery of DHEA to fat depots, where this lipophilic steroid could accumulate.

An additional, and perhaps the most intriguing, finding of this study was that insulin increased the $M_{C} R_{D H E A}$ only in men, and did not affect the $\mathrm{MCR}_{\text {DHEA }}$ in women. While we were surprised by this finding, insulin's sex-specific action on the $\mathrm{MCR}_{\text {DHEA }}$ was not entirely unexpected. In contrast to reports in men (24), serum DHEA levels in women do not fall during an acute insulin infusion $(44,45)$ and do not change during chronic suppression of serum insulin levels (27a). These observations suggest that insulin lowers serum DHEA levels in men, but does not affect circulating DHEA levels in women.

Several other lines of evidence also suggest that sex-based differences in DHEA metabolism exist. In vivo hydrolysis of isotopically labeled DHEA-sulfate to DHEA appears to be greater in women than in men (46), as is the serum ratio of DHEA to DHEA-sulfate (47). Some studies, although not all, suggest that serum DHEA and DHEA-sulfate levels are lower in women than in men $(1,27,47,48)$, despite the fact that these steroids are almost exclusively of adrenal origin in both sexes (1). A recent genetic study indicates that heritable factors are the primary determinants of circulating DHEA-sulfate concentrations in women, whereas in men heredity plays a minor role and other unidentified factors appear to dominate (49). 
INSULIN - GLUCOSE

CLAMP OR

SALINE INFUSION

DHEA INFUSED AT 1.0 mo/hour
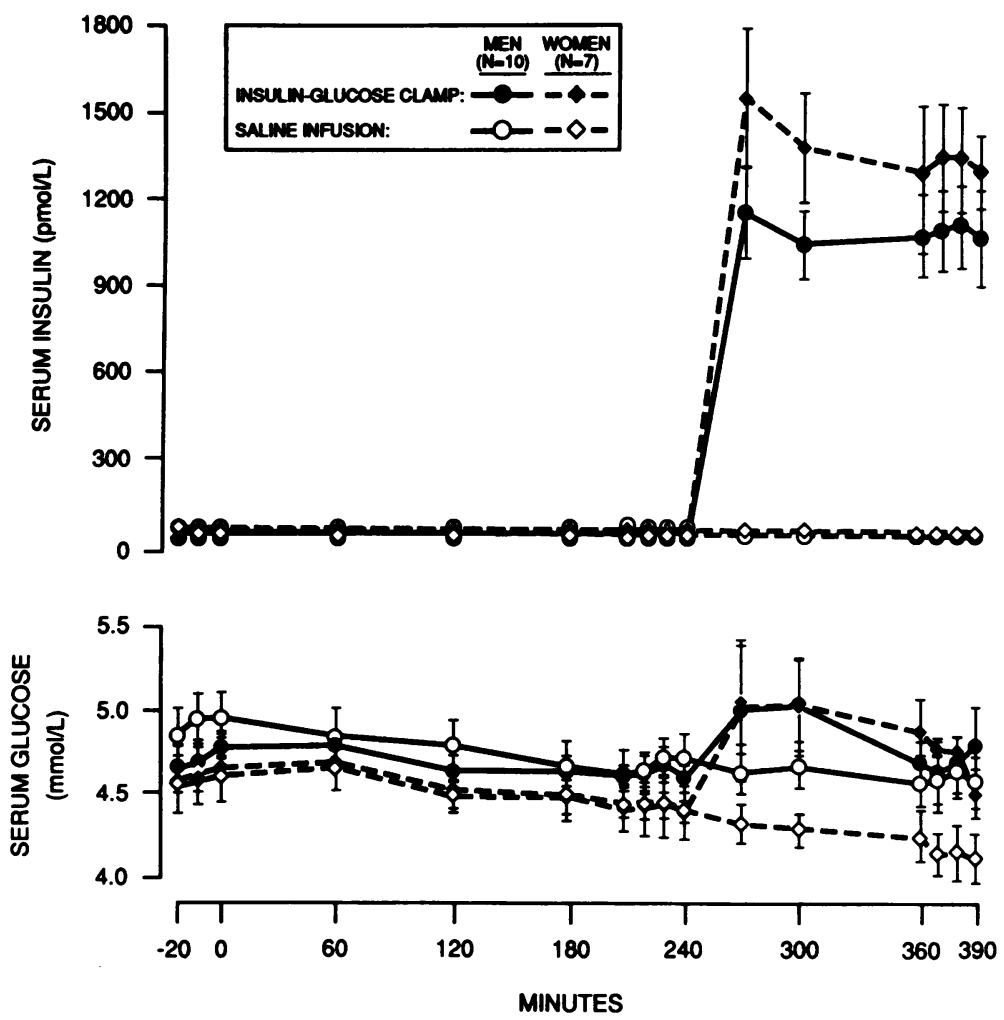

Figure 1. Serum insulin and glucose concentrations in 10 men and 7 women during a hyperinsulinemic-euglycemic clamp study and a saline control study. DHEA was infused intravenously from $0-360 \mathrm{~min}$ at a rate of 3.47 $\mu \mathrm{mol} / \mathrm{h}(1.0 \mathrm{mg} / \mathrm{h})$. At $240 \mathrm{~min}$ either a hyperinsulinemic-euglycemic clamp was initiated with insulin infused at a rate of $21.5 \mathrm{pmol} / \mathrm{kg}$ per $\min (3.0 \mathrm{mU} / \mathrm{kg}$ per min $)$ (insulin-glucose clamp study) or $0.45 \%$ saline was infused (control study).
Collectively, these observations support the idea that DHEA metabolism may be regulated differently in men than in women.

The sex specificity of insulin's acute action on the $\mathbf{M C R}_{\text {DHEA }}$ may explain why the experimental elevation of circulating insulin is associated with a decline in serum DHEA levels in men (24) but not in women $(44,45)$. The reason or reasons for the disparate responses of $\mathbf{M C R}_{\mathrm{DHEA}}$ to acute hyperinsulinemia based on sex is unknown. Although speculative, perhaps the presence of certain sex steroids is necessary for insulin to affect the $\mathrm{MCR}_{\mathrm{DHEA}}$. This would be the case, for example, if a high ambient testosterone concentration were required for maximal insulin-induced vasodilation. In support of this idea, sex steroids have been shown to modulate the vasopressor and vasodilatory effects of several agents (50-53). Furthermore, evidence suggests that differences in circulating sex steroids may account for the differential vascular responses to thromboxane A2 observed between male and female rats (53).

Finally, it should be noted that this study's findings appear to contrast with the report by Farah et al. (32), which described a positive correlation between the $\mathrm{MCR}_{\mathrm{DHEA}}$ and fasting serum insulin levels in normal women. A potential explanation for this apparent discrepancy is that chronic effects of insulin on DHEA metabolism likely differ from acute actions. For example, under chronic conditions hyperinsulinemia has been shown to increase capillary density in muscle (54). If this action of insulin were to extend to other tissues, chronic exposure to hyperinsulinemia could result in increased vascularization of adipose tissue and enhanced delivery of DHEA to fat storage sites. Under acute experimental conditions, this action of insulin would not be observed.

The clinical relevance of these findings is at least threefold. Firstly, some epidemiologic studies report that serum DHEA and/or DHEA-sulfate levels in men are reduced in pathological states characterized by insulin resistance and hyperinsulinemia, such as obesity $(55,56)$, hypertension $(9,57)$, and untreated type II diabetes mellitus (58). The findings of this study suggest that enhancement of the $\mathrm{MCR}_{\mathrm{DHEA}}$ by insulin may contribute to the reduced serum DHEA levels observed in some of these pathologic conditions, at least as far as men are concerned.

Secondly, mounting evidence suggests that DHEA and its ester, DHEA-sulfate, exert multiple antiatherogenic and cardioprotective actions $(3,7-9,11-13)$. A higher serum DHEAsulfate level lowers the risk in men for the development of atherosclerosis $(4-6,8,10)$. An epidemiological association between hyperinsulinemia and macrovascular disease has been well documented $(59,60)$, and it has been proposed recently that hyperinsulinemia may promote atherosclerosis by lowering circulating DHEA and DHEA-sulfate concentrations (7). The findings of this study bolster this hypothesis, in that they support the idea that insulin regulates DHEA metabolism in men under physiological conditions.

Thirdly, we and others have at times extrapolated to women 

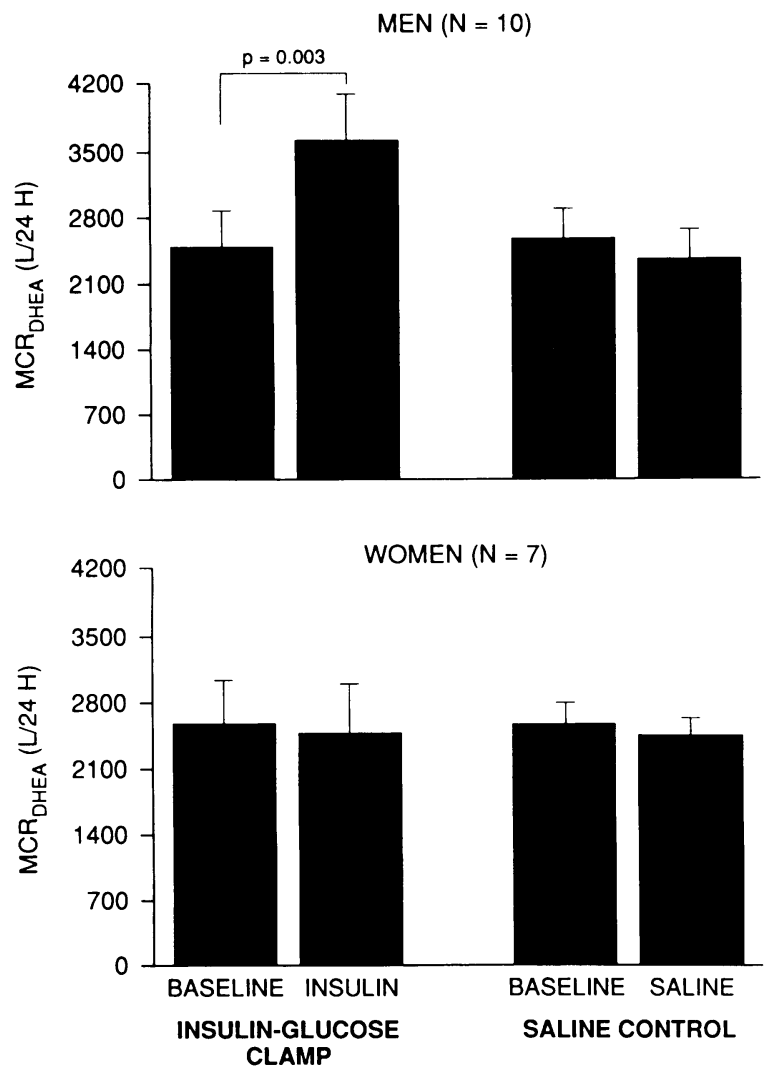

Figure 2. $\mathrm{MCR}_{\mathrm{DHEA}}$ in 10 men and 7 women during a hyperinsulinemiceuglycemic clamp study and a control saline study. For each study $M_{\text {DCREA }}$ was determined at baseline and during either an insulin infusion (insulin-glucose clamp study) or saline infusion (control study).

the results of studies examining insulin's effects on DHEA metabolism that were performed in men, and vice versa (61). The sex specificity of insulin action observed in the present study indicates that this practice may not be valid. Studies need to be performed in both men and women to obtain an accurate understanding of insulin's actions on human DHEA metabolism.

In summary, the results of this study suggest that insulin acutely increases the $\mathrm{MCR}_{\text {DHEA }}$ in men. In contrast, insulin does not appear to acutely change the $\mathrm{MCR}_{\mathrm{DHEA}}$ in women. These findings suggest that a sex-based difference exists in insulin regulation of human DHEA metabolism.

\section{Acknowledgments}

We thank Terre Williams, Roberta O'Brien, and the staff of the General Clinical Research Center (GCRC) for their technical assistance.

These studies were supported in part by National Institutes of Health grants RO1AG-11227 (J. E. Nestler) and RR-00066 (GCRC).

\section{References}

1. Parker, L. N. 1989. Adrenal Androgens in Clinical Medicine. Academic Press, Inc., San Diego. 615 pp.

2. Nieschlag, E., D. L. Loriaux, H. J. Ruder, I. R. Zucker, M. A. Kirschner, and M. B. Lipsett. 1973. The secretion of dehydroepiandrosterone and dehydroepiandrosterone sulphate in man. J. Endocrinol. 57:123-134.

3. Rao. L. G. 1970. Urinary steroid excretion patterns after acute myocardial infarction. Lancet. ii:390-391.
4. Barrett-Connor, E.. K. T. Khaw, and S. S. C. Yen. 1986. A prospective study of dehydroepiandrosterone sulfate, mortality, and cardiovascular disease. N. Engl. J. Med. 315:1519-1524.

5. Slowinska-Srzednicka, J., S. Zgliczynski, M. Ciswicka-Sznajderman, M. Srzednicki, P. Soszynski, M. Biernacka, M. Woroszylska, W. Ruzyllo, and Z. Sadowski. 1989. Decreased plasma dehydroepiandrosterone sulfate and dihydrotestosterone concentrations in young men after myocardial infarction. Atherosclerosis. 79:197-203.

6. Herrington, D. M., G. B. Gordon, S. C. Achuff, J. F. Trejo, H. F. Weisman, P. O. Kwiterovich, and T. A. Pearson. 1990. Plasma dehydroepiandrosterone and dehydroepiandrosterone sulfate in patients undergoing diagnostic coronary angiography. J. Am. Coll. Cardiol. 16:862-870.

7. Nestler. J. E.. J. N. Clore, and W. G. Blackard. 1992. Dehydroepiandrosterone: the "missing link" between hyperinsulinemia and atherosclerosis? FASEB (Fed. Am. Soc. Exp. Biol.) J. 6:3073-3075.

8. Ishihara, F.. K. Hiramatsu, S. Shigematsu, T. Aizawa, A. Niwa, N. Takasu, T. Yamada, and K. Matsuo. 1992. Role of adrenal androgens in the development of arteriosclerosis as judged by pulse wave velocity and calcification of the aorta. Cardiology. 80:332-338.

9. Nafziger, A. N., D. M. Herrington, and T. L. Bush. 1991. Dehydroepiandrosterone and dehydroepiandrosterone sulfate: their relation to cardiovascular disease. Epidemiol. Rev. 13:267-293.

10. Mitchell, L. E., D. L. Sprecher. I. B. Borecki, T. Rice, P. M. Laskarzewski, and D. C. Rao. 1994. Evidence for an association between dehydroepiandrosterone sulfate and nonfatal, premature myocardial infarction in males. Circulation. 89:89-93.

11. Gordon, G. B., D. E. Bush, and H. F. Weisman. 1988. Reduction of atherosclerosis by administration of dehydroepiandrosterone. A study in the hypercholesterolemic New Zealand White rabbit with aortic intimal injury. J. Clin. Invest. 82:712-720.

12. Arad, Y., J. O. Badimon, L. Badimon, W. Hembrec, and H. N. Ginsberg. 1989. Dehydroepiandrosterone feeding prevents aortic fatty streak formation and cholesterol accumulation in cholesterol-fed rabbit. Arteriosclerosis. 9:159-166.

13. Eich, D. M., J. E. Nestler, D. E. Johnson, G. H. Dworkin, D. Ko, A. S. Wechsler, and M. L. Hess. 1993. Inhibition of accelerated coronary atherosclerosis with dehydroepiandrosterone in the heterotopic rabbit model of cardiac transplantation. Circulation. 87:261-269.

14. Saenger. P., and M. New. 1977. Inhibitory action of dehydroepiandrosterone (DHEA) on fibroblast growth. Experientia (Basel). 33:966-967.

15. Nestler, J. E., C. O. Barlascini, J. N. Clore, and W. G. Blackard. 1988. Dehydroepiandrosterone reduces serum low-density lipoprotein levels and body fat but does not alter insulin sensitivity in normal men. J. Clin. Endocrinol. \& Metab. 66:57-61.

16. Haffner. S. M.. L. Mykkänen. R. A. Valdez, and M. S. Katz. 1993. Relationship of sex hormones to lipids and lipoproteins in nondiabetic men. $J$. Clin. Endocrinol. \& Metab. 77:1610-1615.

17. Jesse, R., J. E. Nestler, D. Eich, and M. Hess. 1991. Dehydroepiandrosterone in vivo and in vitro inhibits platelet aggregation. J. Am. Coll. Cardiol. 17 ( Suppl. A):376a. (Abstr.)

18. Schriock, E. D., C. K. Buffington, G. D. Hubert, B. R. Kurtz, A. E. Kitabchi, J. E. Buster, and J. R. Givens. 1988. Divergent correlation of circulatory dehydroepiandrosterone sulfate and testosterone with insulin levels and insulin receptor binding. J. Clin. Endocrinol. \& Metab. 66:1329-1331.

19. Buffington, C. K., J. R. Givens, and A. E. Kitabchi. 1991. Opposing actions of dehydroepiandrosterone and testosterone on insulin sensitivity. In vivo and in vitro studies of hyperandrogenic females. Diabetes. 40:693-700.

20. Buffington, C. K., G. Pourmotabbed, and A. E. Kitabchi. 1993. Case report: amelioration of insulin resistance in diabetes with dehydroepiandrosterone. Am. J. Med. Sci. 306:320-324.

21. Coleman, D. L., E. H. Leiter, and R. W. Schwizer. 1982. Therapeutic effect of dehydroepiandrosterone (DHEA) in diabetic mice. Diabetes. 31:830833.

22. Coleman, D. L., R. W. Schwizer, and E. H. Leiter. 1984. Effect of genetic background on the therapeutic effects of dehydroepiandrosterone (DHEA) in diabetes-obesity mutants and in aged normal mice. Diabetes. 33:26-32.

23. Pashko. L. L.. and A. G. Schwartz. 1993. Antihyperglycemic effect of dehydroepiandrosterone analogue 16 alpha-fluoro-5-androsten-17-one in diabetic mice. Diabetes. 42:1105-1108.

24. Nestler, J. E., K. S. Usiskin. C. O. Barlascini, D. F. Welty, J. N. Clore. and W. G. Blackard. 1989. Suppression of serum dehydroepiandrosterone sulfate levels by insulin: an evaluation of possible mechanisms. J. Clin. Endocrinol. \& Metab. 69:1040-1046.

25. Mortola. J. F., and S. S. C. Yen. 1990. The effects of oral dehydroepiandrosterone on endocrine-metabolic parameters in postmenopausal women. J. Clin. Endocrinol. \& Metab. 71:696-704.

26. Migeon. C. J.. A. R. Keller. B. Lawrence, and T. H. Shepard II. 1957. Dehydroepiandrosterone and androsterone levels in human plasma. Effect of age and sex, day-to-day and diurnal variations. J. Clin. Endocrinol. \& Metab. 17:1051-1062.

27. Carlström, K., S. Brody, N. O. Lunell, A. Lagrelius, G. Mollerstrom, A. 
Pousette, G. Rannevik, R. Stege, and B. von Schoultz. 1988. Dehydroepiandrosterone sulfate and dehydroepiandrosterone in serum: differences related to age and sex. Maturitas. 10:297-306.

27a.Beer, N. A., D. J. Jakubowicz, R. M. Beer. and J. E. Nestler. 1994. Disparate effects of insulin reduction with diltiazem on serum dehydroepiandrosterone sulfate levels in obese, hypertensive men and women. J. Clin. Endocrinol. Metab. In press.

28. Nestler, J. E., N. A. Beer, D. J. Jakubowicz, and R. M. Beer. 1994. Effects of a reduction in circulating insulin by metformin on serum dehydroepiandrosterone sulfate in nondiabetic men. J. Clin. Endocrinol. \& Metab. 78:549-554.

29. Kurtz, B. R., J. R. Givens, S. Komindr, M. D. Stevens, J. G. Karas, J. B. Bittle, D. Judge, and A. E. Kitabchi. 1987. Maintenance of normal circulating levels of $\Delta^{4}$-androstenedione and dehydroepiandrosterone in simple obesity despite increased metabolic clearance rates: evidence for a servo-control mechanism. J. Clin. Endocrinol. \& Metab. 64:1261-1267.

30. Fehér, T., and L. Halmy. 1975. Dehydroepiandrosterone and dehydroepiandrosterone sulfate dynamics in obesity. Can. J. Biochem. 53:215-222.

31. Kirschner, M. A., E. Samojlik, and D. Silber. 1983. A comparison of androgen production and clearance in hirsute and obese women. J. Steroid Biochem. 19:607-614.

32. Farah, M. J., J. R. Givens, and A. E. Kitabchi. 1990. Bimodal correlation between the circulating insulin level and the production rate of dehydroepiandrosterone: positive correlation in controls and negative correlation in the polycystic ovary syndrome with acanthosis nigricans. J. Clin. Endocrinol. \& Metab. 70:1075-1081

33. Hendrikx, A., W. Heyns, and P. de Moor. 1968. Influence of low-calorie diet and fasting on the metabolism of dehydroepiandrosterone sulfate in obese subjects. J. Clin. Endocrinol. \& Metab. 28:1525-1533.

34. Evans, D. J., R. G. Hoffmann, R. K. Kalkhoff, and A. H. Kissebah. 1983. Relationship of androgenic activity to body fat topography, fat cell morphology, and metabolic aberrations in premenopausal women. J. Clin. Endocrinol. \& Metab. 57:304-310.

35. Ellison, P. T. 1984. Correlations of basal oestrogens with adrenal androgens and relative weight in normal women. Ann. Hum. Biol. 11:327-336.

36. Haning, R. V., Jr., R. J. Hackett, C. A. Flood, J. S. Loughlin, Q. Y. Zhao, and C. Longcope. 1993. Plasma dehydroepiandrosterone sulfate serves as a prehormone for $48 \%$ of follicular fluid testosterone during treatment with menotropins. J. Clin. Endocrinol. \& Metab. 76:1301-1307.

37. Bélisle, S., I. Schiff, and D. Tulchinsky. 1980. The use of constant infusion of unlabeled dehydroepiandrosterone for the assessment of its metabolic clearance rate, its half-life, and its conversion into estrogens. J. Clin. Endocrinol. \& Metab. 50:117-121.

38. Nestler, J. E., J. N. Clore, J. F. Strauss III, and W. G. Blackard. 1987. Effects of hyperinsulinemia on serum testosterone, progesterone, dehydroepiandrosterone sulfate, and cortisol levels in normal women and in a woman with hyperandrogenism, insulin resistance and acanthosis nigricans. J. Clin. Endocrinol. \& Metab. 64:180-184.

39. Nestler, J. E., M. A. McClanahan, J. N. Clore, and W. G. Blackard. 1992. Insulin inhibits adrenal 17,20-lyase activity in man. J. Clin. Endocrinol. \& Metab. 74:362-367.

40. Kahn, A. M., C. L. Seidel, J. C. Allen, R. G. O'Neil, H. Shelat, and T. Song. 1993. Insulin reduces contraction and intracellular calcium concentration in vascular smooth muscle. Hypertension. 22:735-742.

41. Juncos, L. A., and S. Ito. 1993. Disparate effects of insulin on isolated rabbit afferent and efferent arterioles. J. Clin. Invest. 92:1981-1985.
42. Feldman, R. D., and G. S. Bierbrier. 1993. Insulin-mediated vasodilation: impairment with increased blood pressure and body mass. Lancet. 342:707-709.

43. Vollenweider, P., L. Tappy, D. Randin, P. Schneiter, E. Jéquier, P. Nicod, and U. Scherrer. 1993. Differential effects of hyperinsulinemia and carbohydrate metabolism on sympathetic nerve activity and muscle blood flow in humans. $J$. Clin. Invest. 92:147-154.

44. Diamond, M. P., D. A. Grainger, A. J. Laudano, K. Starick-Zych, and R. A. DeFronzo. 1991. Effect of acute physiological elevations of insulin on circulating androgen levels in nonobese women. J. Clin. Endocrinol. \& Metab. 72:883-887.

45. Stuart, C. A., and M. Nagamani. 1990. Insulin infusion acutely augments ovarian androgen production in normal women. Fertil. Steril. 54:788-792.

46. Zumoff, B., and H. L. Bradlow. 1980. Sex differences in the metabolism of dehydroepiandrosterone sulfate. J. Clin. Endocrinol. \& Metab. 51:334-336.

47. Zumoff, B., R. S. Rosenfeld, G. W. Strain, J. Levin, and D. K. Fukushima. 1980. Sex differences in the twenty-four-hour mean plasma concentrations of dehydroepiandrosterone (DHA) and dehydroepiandrosterone sulfate (DHAS) and the DHA to DHAS ratio in normal adults. J. Clin. Endocrinol. \& Metab. 51:330333.

48. Orentreich, N., J. L. Brind, R. L. Rizer, and J. H. Vogelman. 1984. Age changes and sex differences in serum dehydroepiandrosterone sulfate concentrations throughout adulthood. J. Clin. Endocrinol. \& Metab. 59:551-555.

49. Rice, T., D. L. Sprecher, I. B. Borecki, L. E. Mitchell, P. M. Laskarzewski, and D. C. Rao. 1993. The Cincinnati Myocardial Infarction and Hormone Family Study: family resemblance for dehydroepiandrosterone sulfate in control and myocardial infarction families. Metab. Clin. Exp. 42:1284-1290.

50. Mills, T. M., V. T. Wiedmeier, and V. S. Stopper. 1992. Androgen maintenance of erectile function in the rat penis. Biol. Reprod. 46:342-348.

51. Farhat, M. Y., and P. W. Ramwell. 1992. Estradiol potentiates the vasopressor response of the isolated perfused rat lung to the thromboxane mimic U46619. J. Pharmacol. Exp. Ther. 261:686-691.

52. Zhang, A., B. T. Altura, and B. M. Altura. 1991. Sexual dimorphism of vascular smooth muscle responsiveness is dependent on anions and estrogen. Steroids. 56:524-526.

53. Masuda, A., R. Mathur, and P. V. Halushka. 1991. Testosterone increases thromboxane A2 receptors in cultured rat aortic smooth muscle cells. Circ. Res. 69:638-643.

54. Holmäng, A., Z. Brzezinska, and P. Björntorp. 1993. Effects of hyperinsulinemia on muscle fiber composition and capitalization in rats. Diabetes. 42:10731081.

55. Šonka, J. 1976. Dehydroepiandrosterone. Metabolic effects. In Acta Universitatis Carolinae. J. Charvát, editor. Universita Karlova Praha, Prague. 171 pp.

56. Lopez-S, A., and W. A. Krehl. 1967. A possible interrelation between glucose-6-phosphate dehydrogenase and dehydroepiandrosterone in obesity. Lancet. ii:485-487.

57. Nowaczynski, W., F. Fragachas, J. Silah, B. Millette, and J. Genest. 1968. Further evidence of altered adrenocortical functions in hypertension: dehydroepiandrosterone secretion rate. Can. J. Biochem. 46:1031-1038.

58. Barrett-Connor, E. 1992. Lower endogenous androgen levels and dyslipidemia in men with non-insulin-dependent diabetes mellitus. Ann. Intern. Med. 117:807-811

59. Reaven, G. M. 1988. Banting lecture 1988. Role of insulin resistance in human disease. Diabetes. 37:1595-1607.

60. DeFronzo, R. A., and E. Ferrannini. 1991. Insulin resistance. A multifaceted syndrome responsible for NIDDM, obesity, hypertension, dyslipidemia and atherosclerotic cardiovascular disease. Diabetes Care. 14:173-194.

61. Nestler, J. E., J. N. Clore, and W. G. Blackard. 1991. Metabolism and actions of dehydroepiandrosterone in humans. J. Steroid Biochem. Mol. Biol. 40:599-605. 